\title{
Correction: Cost-effectiveness of risk stratified medication management for reducing premature cardiovascular mortality in Kenya
}

\section{The PLOS ONEStaff}

There are errors in the Funding statement. The publisher apologizes for these errors. The correct Funding statement is as follows: This Collection was supported by TEPHINET, a program of The Task Force for Global Health, Inc., via Cooperative Agreement number NU2GGH001873, funded by the Centers for Disease Control and Prevention. Its contents are solely the responsibility of the authors and do not necessarily represent the official views of the Centers for Disease Control and Prevention, the U.S. Department of Health and Human Services, The Task Force for Global Health, Inc., or TEPHINET.

\section{Reference}

1. Subramanian S, Hilscher R, Gakunga R, Munoz B, Ogola E (2019) Cost-effectiveness of risk stratified medication management for reducing premature cardiovascular mortality in Kenya. PLoS ONE 14(6) e0218256. https://doi.org/10.1371/journal.pone.0218256 PMID: 31237910

G open Access

Citation: The PLOS ONE Staff (2020) Correction: Cost-effectiveness of risk stratified medication management for reducing premature cardiovascular mortality in Kenya. PLOS ONE 15 (5): e0233139. https://doi.org/10.1371/journal. pone.0233139

Published: May 7, 2020

Copyright: @ 2020 The PLOS ONE Staff. This is an open access article distributed under the terms of the Creative Commons Attribution License, which permits unrestricted use, distribution, and reproduction in any medium, provided the original author and source are credited. 